\title{
Association between microalbuminuria and MYH9 gene polymorphisms in hypertensive Iraqi patients with metabolic syndrome
}

\author{
Alaa Fahem Jasim', Fadhil Jawad Al-Tu'ma ${ }^{1 *}$, Dhafir Abdul-Mahdi Faisal² \\ 'Department of Chemistry and Biochemistry, College of Medicine, University of Kerbala, Kerbala, Iraq. \\ ${ }^{2}$ College of Pharmacy, University of Kufa, Najaf, Iraq. \\ *Correspondence to: Fadhil Jawad Al-Tu'ma (E-mail: fadhil.jawad@uokerbala.edu.iq) \\ (Submitted: 21 December 2020 - Revised version received: 09 January 2021 - Accepted: 19 February 2021 - Published online: 26 April 2021)
}

\begin{abstract}
Objective The presented work aimed to study the correlation between microalbuminuria and MYH9 (T>C) (rs3752462) gene polymorphisms in metabolic syndrome of Iraqi patients.

Methods This study was a cross-sectional study. Sample size was 140 persons of both gender selected randomly between April 1, 2019 and Aug. 15, 2020. They are divided into two groups, 80 with metabolic syndrome patients and 60 with control groups subdivided into another two groups: 30 persons with obese and 30 persons without obese. The distribution of sample according to the gender, the number of males had metabolic syndrome were 47 and female 33, but in obese healthy control the number of males were 19 and female 11, while in non-obese healthy control the number of males were 15 and female 15. The age groups were ranged between 40 and 60 years. Typing of MYH9 was performed by refractory mutation system-polymerase chain reaction (ARMS-PCR). The current study was performed to investigate the SNPs that affected MYH9 gene which was (T>C) (rs3752462).

Results There was a significant difference between blood sugar, HbA1c, total cholesterol, TG, VLDL-C, LDL-C, blood urea, microalbuminuria, $\mathrm{BMI}$, and HOMA-IR in metabolic syndrome patients as compared with healthy control groups $(P \leq 0.01)$. The significant result $(P \leq 0.01)$ were appeared between TT for MYH9 genotype patients and obese control with biochemical parameters (Blood glucose, HbA1C, TC, TG, VLDL-C, and LDL-C). The correlation between TT SNP for MYH9 genotype patients and non-obese control with biochemical parameters is significant result ( $P \leq 0.01$ and $P \leq 0.05$ ) (Blood glucose, HbA1c, insulin, $\mathrm{TC}, \mathrm{TG}, \mathrm{VLDL}-\mathrm{C}$, LDL-C, urea, and microalbuminuria). The significant result $(P \leq 0.01$ and $P \leq 0.05$ ) appeared between $C T$ for MYH9 genotype patients and obese control with biochemical parameters (Blood glucose, $\mathrm{HbA1C}$, TC, TG, and VLDL-C) respectively.

Conclusions There is a significant difference between blood glucose, HbA1C, total cholesterol, TG, VLDL-C, LDL-C, blood urea, microalbuminuria, BMI, and HOMA-IR in metabolic syndrome patients and healthy control groups $(P \leq 0.01)$. Also, a significant result $(P \leq$ 0.01 ) obtained between TT for MYH9 genotype patients and obese and non-obese control with some biochemical parameters. $(P \leq 0.01$ and $P \leq 0.05$ ). The significant results ( $P \leq 0.01$ and $P \leq 0.05$ ) appear between $C T$ for $M Y H 9$ genotype patients and obese control with some biochemical parameters.

Keywords Metabolic syndrome, Albumins, MYH9, genotype, ARMS-PCR
\end{abstract}

\section{Introduction}

Metabolic syndrome is associated with an increased risk of type 2 diabetes mellitus (DM) and cardiovascular disease (CVD) ${ }^{1-4}$ Metabolic syndrome is the coincidence in a person of interrelated risk factors for CVD and diabetes. These factors include hyperglycemia, raised blood pressure, elevated triglyceride level, reduced HDL-C, and obesity (particularly central adiposity). ${ }^{5}$ Various reports indicate that the individual of the metabolic syndrome is associated with increased risk for both CVD and type 2 diabetes. ${ }^{6,7}$

Higher blood pressure, the shorter life expectancy, people with high blood pressure run a higher risk of having a stroke (which damages the brain) or a heart attack. If left untreated for a long time, high blood pressure can lead to kidney failure and even damage the eye. It can also make the heart abnormally large and less efficient (a condition called 'left ventricular hypertrophy'). This can lead to heart failure, which is when the pumping action of the heart becomes less effective. It also known as hypertension - rarely makes people feel ill. It is sometimes called a 'silent threat' because there are usually no symptoms, and it very often goes undiagnosed. ${ }^{8}$ Blood pressure is regulated by renin-angiotensin system (RAS).

$\mathrm{DM}$ is a group of metabolic diseases characterized by hyperglycemia resulting from defects in insulin secretion, activation, or action. ${ }^{9}$ The effects of DM include long-term damage, dysfunction, and failure of various organs. DM may present with characteristic symptoms such as thirst, polyuria, blurring of vision, and weight loss.

Most cases of DM fall into three general broad categories: type $1 \mathrm{DM}$ (T1DM), type $2 \mathrm{DM}$ (T2DM), and gestational $\mathrm{DM}(\mathrm{GDM})$ and another type is a specific type of diabetes. ${ }^{10}$ Blood pressure is the force of blood against the walls of arteries. Blood pressure rises and falls throughout the day. When blood pressure stays elevated over time, it's called high blood pressure. $^{11}$

The myosin heavy chain 9 (MYH9) gene, which is located on chromosome 22 q12.3-13.2, has 40 exons that encode a protein of approximately $224,000 \mathrm{kDa}$. The protein is a non-muscle myosin heavy chain that dimerizes to form the motor domain of non-muscle myosin IIA, an important motor protein found in most cells of the body. ${ }^{12}$ The MYH9 gene is expressed in fibroblasts, erythroblasts, and kidney cells. ${ }^{13}$ Abnormal MYH9 expression, positioning, or function change leads to cytoskeleton damage, causing proteinuria, hematuria, or renal failure in some cases. ${ }^{14} \mathrm{MYH} 9$ has also been shown to be a major susceptibility gene for nephropathy, and hypertension. This association has also been demonstrated in various populations, ranging from African-Americans and Hispanic Americans to Europeans. ${ }^{15-18}$ Freedman et al. found that mutations in MYH9 
associated with African-American proteinuria caused by high blood pressure were associated with end-stage renal disease (ESRD). ${ }^{19}$ Other investigator show that the rs3752462 was associated with chronic kidney disease (CKD) ${ }^{20}$

The present study was aimed to investigate the correlation between microalbuminuria and MYH9 (T>C) ( $\mathrm{rs3752462)}$ gene polymorphisms in metabolic syndrome of Iraqi patients and its correlation with various biochemical markers.

\section{Materials and Methods}

This work was designed as a cross-sectional study, 140 subjects were recruited, about 80 of them with metabolic syndrome and the other 60 of apparently healthy individuals randomly with age ranged between 40 and 50 years between April 1, 2019 and Aug. 15, 2020. The patients were diagnosed by a specialist physician at Al-Hassan Medical Center for Endocrinology, in the Al-Hussein Medical City / Kerbala Health Directorate - Iraq. It should be noted that Kerbala is a holy city and one of the biggest cities in Iraq. The study protocol was approved by the Medical Ethics committee of College of Medicine/ University of Kerbala and the Kerbala Health Directorate.

The glycated hemoglobin (HbAlc) level was assessed, using the COBAS HbA1c kit (Roche, Germany), by COBAS INTEGRA ${ }^{\star} 400$ (Roche, Germany); the turbidity measurement was made with a spectrophotometer to determine the light absorbance. The amount of light blocked by particle suspension depends not only on concentration, but also on the particle size, because particles tend to aggregate and settle out of suspension, consequently sample handling becomes critical. Blood samples were collected from T2DM patients and the control group in EDTA tubes. Total genomic DNA was extracted from the peripheral blood sample $(1 \mathrm{ml})$, using the kit ReliaPrep ${ }^{\text {Tn }}$ Blood gDNA Miniprep System obtained from (Promega USA). The protocol was followed according to the manufacturers' recommendations. DNA concentration and purity were measured, using a BioDrop (UK).

Genotyping of MYH9 (T>C) (rs3752462) polymorphism was performed by tetra-primer amplification refractory mutation system-polymerase chain reaction technique (T-ARMSPCR) with the use of thermocycler (Cleaver/UK). Outer forward: $\quad 5$ 'AGCTGCAGCCCAGAGCATCTCCTCTAAT-3'; Outer reverse: 5'-TCGTTTGAGCAGCTGTGCATCAATTACA-3'; Inner forward: 5'-CAGGTGTG AGGTCAAAGCAAGCCTTGT-3'. Inner reverse: 5'-ATCGACC TCATTGAGA AGCCAGTGAGGAG-3'. The amplification was performed in a total volume of $25 \mu \mathrm{l}$ consisted of $12.5 \mu$ of Taq green master mix (Promega, USA) 1, 1, 1 and $1 \mu \mathrm{l}$ of outer forward, reverse forward, inner forward and inner reverse primers, respectively and $5 \mu \mathrm{l}$ genomic DNA as a template. The PCR reaction program protocol was $94^{\circ} \mathrm{C}$ for 5 min followed by 35 cycles of $94^{\circ} \mathrm{C}$ for $35 \mathrm{~s}, 55^{\circ} \mathrm{C}$ for $45 \mathrm{~s}$, $72{ }^{\circ} \mathrm{C}$ for $55 \mathrm{~s}$ and a final cycle $72{ }^{\circ} \mathrm{C}$ for $5 \mathrm{~min}$. The amplification products were $381 \mathrm{bp}$ for control band. The product of amplification was analyzed by $2 \%$ agarose gel electrophoresis.

\section{Results}

In the present study that is shown in Table 1, there was a significant difference between blood glucose, HbAlc, total cholesterol, TG, VLDL-C, LDL-C, blood urea, microalbuminuria, BMI, and HOMA-IR in metabolic syndrome patients and

\begin{tabular}{|c|c|c|c|c|}
\hline \multirow{3}{*}{ Parameters } & \multicolumn{3}{|c|}{ Mean \pm SD } & \multirow{3}{*}{$P$ value } \\
\hline & \multirow{2}{*}{ Patients } & \multicolumn{2}{|c|}{ Control Groups } & \\
\hline & & Obese & Non-Obese & \\
\hline Blood glucose, mg/dl & $244.31 \pm 98.28$ & $112.33 \pm 27.22$ & $110.87 \pm 17.31$ & $\leq 0.01$ \\
\hline HbA1c\% & $9.30 \pm 2.15$ & $6.08 \pm 0.73$ & $5.64 \pm 0.48$ & $\leq 0.01$ \\
\hline Insulin, $\mu \mathrm{U} / \mathrm{ml}$ & $14.8 \pm 4.48$ & $14.37 \pm 3.23$ & $13.13 \pm 2.30$ & 0.13 \\
\hline $\mathrm{TC}, \mathrm{mg} / \mathrm{dl}$ & $178.28 \pm 47.32$ & $124.07 \pm 23.71$ & $120.00 \pm 22.57$ & $\leq 0.01$ \\
\hline $\mathrm{TG}, \mathrm{mg} / \mathrm{dl}$ & $254.29 \pm 101.50$ & $114.30 \pm 25.09$ & $107.50 \pm 20.89$ & $\leq 0.01$ \\
\hline $\mathrm{HDL}-\mathrm{C}, \mathrm{mg} / \mathrm{dl}$ & $34.95 \pm 9.96$ & $33.60 \pm 5.74$ & $35.47 \pm 6.78$ & 0.68 \\
\hline VLDL-C, mg/dl & $50.81 \pm 20.76$ & $22.83 \pm 4.56$ & $20.40 \pm 4.23$ & $\leq 0.01$ \\
\hline LDL-C, mg/dl & $100.70 \pm 43.28$ & $63.93 \pm 25.59$ & $61.97 \pm 27.24$ & $\leq 0.01$ \\
\hline Urea, mg/dl & $35.09 \pm 12.97$ & $29.93 \pm 6.76$ & $26.40 \pm 7.08$ & $\leq 0.01$ \\
\hline Creatinine, $\mathrm{mg} / \mathrm{dl}$ & $0.95 \pm 0.426$ & $0.90 \pm 0.22$ & $0.87 \pm 0.18$ & 0.50 \\
\hline Microalbuminuria & $50.08 \pm 77.95$ & $13.83 \pm 20.85$ & $13.40 \pm 5.33$ & $\leq 0.01$ \\
\hline $\mathrm{BMI}, \mathrm{kg} / \mathrm{m}^{2}$ & $37.48 \pm 1.98$ & $37.01 \pm 1.82$ & $23.78 \pm 1.00$ & $\leq 0.01$ \\
\hline HOMA-IR & $8.4 \pm 3.02$ & $4.05 \pm 1.5$ & $3.66 \pm 1.1$ & $\leq 0.01$ \\
\hline
\end{tabular}

(HbA1c) glycated hemoglobin A1c, (TG) triglycerides, (TC) total cholesterol, (HDL-C) high-density lipoproteincholesterol, (VLDL-C) very low density lipoprotein-cholesterol, (LDL-C) low density lipoprotein-cholesterol, (BMI) body mass index, (HOMA-IR) homeostatic model assessment of insulin resistance. 


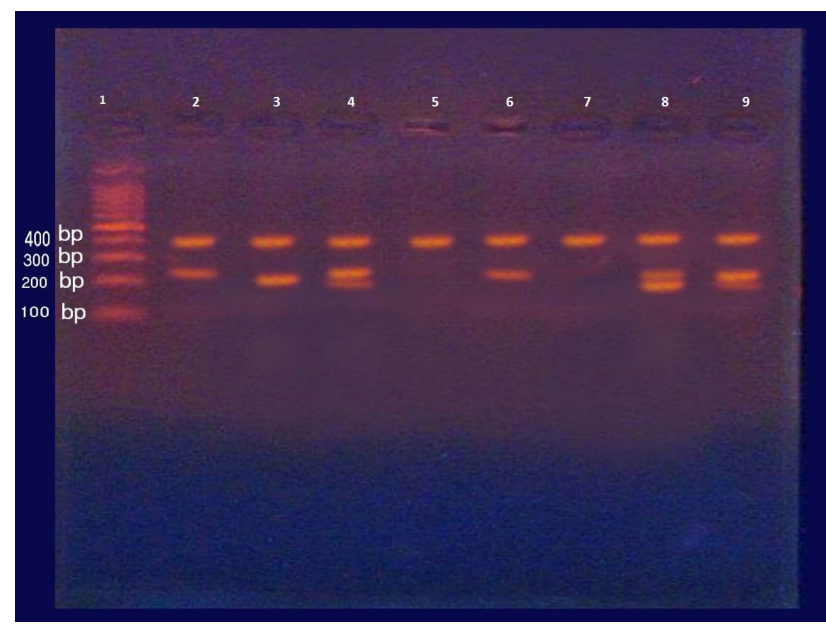

Fig. 1 Amplification of SNP of MYH9 (T>C) was showed in this figure

healthy control groups $(P \leq 0.01)$. While a non-significant differences between metabolic syndrome patients and healthy control groups regarding insulin $(P=0.13)$, HDL-C $(P=0.68)$, and serum creatinine $(P=0.50)$.

The amplification of $M Y H 9$ ( $\mathrm{T}>\mathrm{C})$ gene polymorphism was observed in 381 bp as shown in Fig. 1.

Lane 1: Represented DNA marker 100 - 1000 bp.

Lane 4, 8 and 9: Represented heterozygote (CT) and internal control of $(\mathrm{T}>\mathrm{C})$ SNP of MYH9 gene were showed in (381 bp, $234 \mathrm{bp}$ and $201 \mathrm{bp}$ ).

Lane 2 and 6: Represented mutant type (CC) and internal control of (T>C) SNP of MYH9 gene were showed in (381 bp and $201 \mathrm{bp}$ ).

\begin{tabular}{|c|c|c|c|}
\hline \multirow{2}{*}{$\begin{array}{l}\text { Patients Group } \\
\text { Mean of Parameters }\end{array}$} & \multicolumn{3}{|c|}{ MYH9 (T>C) } \\
\hline & TT & Ст & CC \\
\hline No. of patients & 33 & 42 & 5 \\
\hline Blood glucose, mg/dl & 239.78 & 256.67 & 185.25 \\
\hline $\mathrm{HbA} 1 \mathrm{c} \%$ & 9.236 & 9.395 & 9.42 \\
\hline Insulin, $\mu \mathrm{U} / \mathrm{ml}$ & 15.42 & 14.3 & 16 \\
\hline $\mathrm{TC}, \mathrm{mg} / \mathrm{dl}$ & 182.09 & 173.97 & 172.75 \\
\hline $\mathrm{TG}, \mathrm{mg} / \mathrm{dl}$ & 245.57 & 268.82 & 146.75 \\
\hline $\mathrm{HDL}-\mathrm{C}, \mathrm{mg} / \mathrm{dl}$ & 37.12 & 32.85 & 40 \\
\hline VLDL-C, mg/dl & 50.03 & 53.45 & 27.25 \\
\hline LDL-C, mg/dl & 103.57 & 95.42 & 113.25 \\
\hline Urea, mg/dl & 35.06 & 34.95 & 36.5 \\
\hline Creatinine, mg/dl & 0.97 & 0.94 & 0.88 \\
\hline Microalbuminuria & 50.30 & 55.87 & 17 \\
\hline BMI, $\mathrm{kg} / \mathrm{m}^{2}$ & 37.28 & 37.63 & 36.57 \\
\hline
\end{tabular}

(HbA1c) glycated hemoglobin A1c, (TG) triglycerides, (TC) total cholesterol, (HDL-C) high-density lipoprotein-cholesterol, (VLDL-C) very low density lipoprotein-cholesterol, (LDL-C) low density lipoprotein-cholesterol, (BMI) body mass index.

Lane 3 : Represented wild type (TT) and internal control of (T>C) SNP of MYH9 gene were showed in (381 bp and 234 bp).

Lane 5 and 7: Represented internal control of (CC) of MYH9 gene were showed in (382 bp).

\begin{tabular}{|c|c|c|c|c|c|c|}
\hline \multirow{3}{*}{$\begin{array}{l}\text { Control Groups } \\
\text { Mean of Parameters }\end{array}$} & \multicolumn{6}{|c|}{ MYH9 (T>C) } \\
\hline & \multicolumn{3}{|c|}{ Obese Control } & \multicolumn{3}{|c|}{ Non obese control } \\
\hline & TT & Ст & CC & TT & CT & $\mathrm{CC}$ \\
\hline No. of subjects & 21 & 8 & 1 & 30 & 0 & 0 \\
\hline Blood glucose, mg/dl & 111.52 & 117.12 & 91 & 110.86 & / & / \\
\hline $\mathrm{HbA} 1 \mathrm{c}, \%$ & 6.03 & 6.23 & 5.7 & 5.63 & / & / \\
\hline Insulin, $\mu \mathrm{U} / \mathrm{ml}$ & 14.85 & 13.5 & 11 & 13.13 & / & l \\
\hline $\mathrm{TC}, \mathrm{mg} / \mathrm{dl}$ & 121.57 & 130.75 & 123 & 120 & / & / \\
\hline $\mathrm{TG}, \mathrm{mg} / \mathrm{dl}$ & 113.28 & 116.37 & 119 & 107.5 & / & / \\
\hline HDL-C, mg/dl & 33.09 & 35.25 & 31 & 35.46 & / & / \\
\hline VLDL-C, mg/dl & 22.85 & 23 & 21 & 20.4 & / & / \\
\hline LDL-C, mg/dl & 61.09 & 70.87 & 68 & 61.96 & / & / \\
\hline Urea, mg/dl & 30.66 & 29.25 & 20 & 26.4 & / & / \\
\hline Creatinine, mg/dl & 0.88 & 0.95 & 0.8 & 0.87 & / & / \\
\hline Microalbuminuria & 15.09 & 11.5 & 6 & 13.4 & / & / \\
\hline BMI, $\mathrm{kg} / \mathrm{m}^{2}$ & 36.80 & 37.65 & 36.3 & 23.78 & / & / \\
\hline
\end{tabular}

(HbA1c) glycated hemoglobin A1c, (TG) triglycerides, (TC) total cholesterol, (HDL-C) high-density lipoproteincholesterol, (VLDL-C) very low density lipoprotein-cholesterol, (LDL-C) low density lipoprotein-cholesterol, (BMI) body mass index 
Table 4. The correlation between SNP (T>C) for MYH9 genotype and biochemical parameters

\begin{tabular}{|c|c|c|c|c|c|c|}
\hline \multicolumn{7}{|c|}{ MYH9 (T>C) } \\
\hline & \multicolumn{2}{|c|}{ TT } & \multicolumn{2}{|c|}{ СТ } & \multicolumn{2}{|c|}{ CC } \\
\hline Biochemical parameters & $\begin{array}{l}\text { Patients vs. } \\
\text { Obese control }\end{array}$ & $\begin{array}{c}\text { Patients vs. } \\
\text { Non-Obese } \\
\text { control }\end{array}$ & $\begin{array}{l}\text { Patients vs. } \\
\text { Obese control }\end{array}$ & $\begin{array}{l}\text { Patients vs. } \\
\text { Non-Obese } \\
\text { control }\end{array}$ & $\begin{array}{l}\text { Patients vs. } \\
\text { Obese control }\end{array}$ & $\begin{array}{c}\text { Patients vs. } \\
\text { Non-Obese } \\
\text { control }\end{array}$ \\
\hline Blood sugar, mg/dl & $\leq 0.01$ & $\leq 0.01$ & $\leq 0.01$ & - & 0.3 & - \\
\hline $\mathrm{HbA1c} \%$ & $\leq 0.01$ & $\leq 0.01$ & $\leq 0.01$ & - & 0.097 & - \\
\hline Insulin, $\mu \mathrm{u} / \mathrm{ml}$ & 0.6 & $\leq 0.01$ & 0.7 & - & 0.6 & - \\
\hline $\mathrm{TC}, \mathrm{mg} / \mathrm{dl}$ & $\leq 0.01$ & $\leq 0.01$ & $\leq 0.01$ & - & 0.6 & - \\
\hline $\mathrm{TG}, \mathrm{mg} / \mathrm{dl}$ & $\leq 0.01$ & $\leq 0.01$ & $\leq 0.01$ & - & 0.5 & - \\
\hline HDL-C, mg/dl & 0.2 & 0.5 & 0.4 & - & 0.2 & - \\
\hline VLDL-C, mg/dl & $\leq 0.01$ & $\leq 0.01$ & $\leq 0.01$ & - & 0.4 & - \\
\hline $\mathrm{LDL}-\mathrm{C}, \mathrm{mg} / \mathrm{dl}$ & $\leq 0.01$ & $\leq 0.01$ & 0.1 & - & 0.7 & - \\
\hline Urea, mg/dl & 0.24 & $\leq 0.01$ & 0.16 & - & 0.6 & - \\
\hline Creatinine, mg/dl & 0.5 & 0.3 & 0.9 & - & 0.7 & - \\
\hline Microalbuminuria & 0.07 & $\leq 0.05$ & 0.13 & - & 0.6 & \\
\hline
\end{tabular}

(HbA1c) glycated hemoglobin A1c, (TG) triglycerides, (TC) total cholesterol, (HDL-C) high-density lipoprotein-cholesterol, (VLDL-C) very low density lipoproteincholesterol, (LDL-C) low density lipoprotein-cholesterol.

\section{Discussion}

Metabolic syndrome and hypertension verified the convincing association with microalbuminuria in both females OR $=3.34 ; 95 \%(\mathrm{CI} 2.45-4.55)$ and males $\mathrm{OR}=2.51 ; 95 \%(\mathrm{CI}$ 1.63-3.86) ${ }^{21}$ (Table 3 ). The most common component of metabolic syndrome in our sample was shown to be central obesity and DM followed by hypertriglyceridemia and hypertension; this disagrees with the Indian study, which showed that the main component was hypertension $(98.37 \%)$, followed by dyslipidemia (77.05\%), hyperglycemia (75.41\%), and obesity $(59.02 \%) .22$

Most of the obese who showed metabolic syndrome were not exercising, but no significant association was found between metabolic syndrome and practicing exercises. The heritage family study in the United States showed that exercise training resulted in improvement in the metabolic profile of the participants; the prevalence of metabolic syndrome was decreased from $16.9 \%$ before training to $11.8 \%$ after training. ${ }^{23}$

The higher prevalence of high TG in our country relative to most of the studies elsewhere might be due to higher intake simple carbohydrates and higher ratio of simple to complex carbohydrate consumption by the Persian people. ${ }^{24} \mathrm{We}$ observed higher prevalence of hypertriglyceridemia in Iranian males similar to findings in most other countries. ${ }^{25}$

Older adults are highly susceptible to overweight and obesity due to reduced mobility. ${ }^{26}$ Kuchak and colleagues, as well as Simoes and colleagues, reported that a lack of physical activity program and movement in older adults can intensify the growth of body mass and obesity. ${ }^{27,28}$

Dyslipidemia is one of the major risk factors for coronary heart disease besides age, family history, cigarette smoking, hyperglycemia, and hypertension. The prevalence of dyslipidemia varies widely according to the ethnic, socioeconomic, and cultural characteristics of distinct population groups. $^{29}$

Hypertriglyceridemia was independently associated with DM. A similar association between hypertriglyceridemia and HbAlc was reported in a Russian study. ${ }^{30}$ The present study showed the independent risk factors of the different types of dyslipidemia by multivariate analysis. DM and hypertension were independent risk factors for hypercholesterolemia. A study from Saudi Arabia also reported same association between DM, hypertension, and hypercholesterolemia. ${ }^{31}$

The mean value of HOMA-IR was significantly higher in adult male with essential hypertension when compared with that of controls. Systolic blood pressure and diastolic blood pressure show positive correlation with HOMA-IR but was significant only with systolic blood pressure. This finding is consistent with the findings of some other investigators of other countries. ${ }^{32,33}$ PA Sarafidis and AN Lasaridis was designed to determine the validity and the reproducibility of HOMA-IR, 1/HOMA-IR, QUICKI and McAuley's index in a population of patients that have developed hypertension before type II diabetes. $^{34}$

An elevated serum creatinine level is also a late sign of renal damage in essential hypertension with frankly elevated serum creatinine values predict a poor prognosis in patients with hypertension. ${ }^{35}$

A study by Wachtell et al in 2002 showed an association with raised microalbuminuria and increased risk of heart attacks and stroke. Among the patients with hypertension. ${ }^{36}$ The prevalence of microalbuminuria was also higher among those with hypertensive retinopathy in our study and it was statistically significant. Microalbuminuria is more prevalent in essential hypertensive with target organ dysfunction. ${ }^{36}$ 
The amplification of SNP of MYH9 (T>C) was showed in 381 bp as in Fig 3.

\section{Association between MYH9 (T >C) SNP and biochemical parameters}

The results in current study are shown in Tables 2-4. The correlation between metabolic syndrome patients and control groups have MYH9 (T>C) SNP with biochemical parameters (Blood glucose, HbA1c, Insulin, TC, TG, HDL-C, VLDL-C, LDL-C, urea, creatinine, microalbuminuria, and BMI).

The significant results $(P \leq 0.01)$ appear between TT for MYH9 genotype patients and obese control with biochemical parameters (Blood glucose, HbA1c, TC, TG, VLDL-C, and LDL-C).

The correlation between TT SNP for MYH9 genotype patients and non-obese control with biochemical parameters is significant result ( $P$ value $\leq 0.01$ and $P \leq 0.05)$ (Blood glucose, HbA1c, insulin, TC, TG, VLDL-C, LDL-C, Bl. urea, and microalbuminuria).

The significant results $(P \leq 0.01$ and $P \leq 0.05)$ appear between CT for MYH9 genotype patients and obese control with biochemical parameters (Blood glucose, HbA1c, TC, TG, and VLDL-C).

The non-significant results $(P$-value $>0.01)$ are appear between CC for MYH9 genotype patients and obese control with biochemical parameters (Blood glucose, $\mathrm{HbA} 1 \mathrm{c}$, insulin, TC, TG, HDL-C, VLDL-C, LDL-C, urea, creatinine, and microalbuminuria).

The correlation between TT SNP for MYH9 genotype patients and obese control with biochemical parameters (insulin, HDL-C, urea, creatinine and microalbuminuria) is non-significant $(P>0.01)$.

The non-significant results $(P>0.01)$ showed between TT SNP for MYH9 genotype patients and non-obese control with biochemical parameters (HDL-C and creatinine).

The correlation between CT SNP for MYH9 genotype patients and obese control with biochemical parameters (Insulin, HDL-C, LDL-C, urea, creatinine, and microalbuminuria) is non-significant $(P>0.01)$.

The results in current study that are shown in the same tables that the correlation between metabolic syndrome patients and control groups have MYH9 (T>C) SNP with biochemical parameters (Blood glucose, HbAlc, insulin, TC, TG, HDL-C, VLDL-C, LDL-C, urea, creatinine, microalbuminuria, and $\mathrm{BMI}$ ).

There is a difference in the distribution of the CC, CT, and TT genotypes at rs3752462 in patients with CKD with SBP $\geq$
$140 \mathrm{mmHg}$ and SBP $<140 \mathrm{mmHg}$. The multivariate analysis showed that the CC genotype at rs 3752462 was associated with a lower risk of concurrent higher SBP than the TT genotype in CKD patients. This result provides evidence that there is a genetic link between $\mathrm{MYH} 9$ and hypertension in patients with CKD in China. ${ }^{37}$

It is found that MYH9 SNP rs3752462 is involved in the susceptibility of CKD patients to hypertension. Multivariate logistic regression analysis indicated that the CC genotype was a protective factor against higher SBP in patients with CKD. It also indicated that the mutation of a $\mathrm{C}$ allele to a $\mathrm{T}$ allele can lead to an SBP increase. . $^{38,39}$

The minor allele of SNP rs3752462 is associated with an increased risk of DKD. The results suggest that MYH9 rs3752462 might play an important role in the risk of DKD in the Chinese Han population..$^{40}$ MYH9 rs3752462 was associated with cerebrovascular blood flow (CBF) in patients with type 2 diabetes. ${ }^{41}$ Albuminuria is highly associated with Indian blood quantum in this population suggesting a strong genetic susceptibility to CKD. ${ }^{42}$

\section{Conclusion}

1. There is a significant difference between blood glucose, HbA1c, total cholesterol, TG, VLDL-C, LDL-C, blood urea, microalbuminuria, BMI, and HOMA-IR in metabolic syndrome patients and healthy control groups $(P \leq$ $0.01)$.

2. Most of metabolic syndrome patients are found in age group of 40-49 years.

3. The significant result $(P \leq 0.01)$ appear between TT for MYH9 genotype patients and obese control with biochemical parameters (Blood glucose, HbAlc, TC, TG, VLDL-C, and LDL-C).

4. The correlation between TT SNP for MYH9 genotype patients and non-obese control with biochemical parameters is significant result $(P \leq 0.01$ and $P$-value $\leq 0.05)$ (Blood glucose, HbA1c, insulin, TC, TG, VLDL-C, LDL$\mathrm{C}$, urea, and microalbuminuria).

5. The significant result $(P \leq 0.01$ and $P \leq 0.05)$ appear between CT for MYH9 genotype patients and obese control with biochemical parameters (Blood sugar, HbA1c, TC, TG, and VLDL-C).

\section{Conflict of Interest}

None

7. Hunt, Kelly, et al. NCEP versus WHO metabolic syndrome in relation to all cause and cardiovascular mortality in the San Antonio Heart Study (SAHS). Diabetes, 2003:52

8. Hansen, ML, Gunn, PW, Kaelber, DC. Underdiagnosis of hypertension in children and adolescents. Jama, 2007:298.8:874-879.

9. American Diabetes Association, et al. Standards of medical care in diabetes - 2010. Diabetes Care, 2010;33(1):S11-S61.

10. Baynes, HW. Classification, pathophysiology, diagnosis and management of diabetes mellitus. J Diabe Metab, 2015;6.5:1-9.

11. Chobanian, AV. National heart, lung, and blood institute joint national committee on prevention, detection, evaluation, and treatment of high blood pressure; national high blood pressure education program 
coordinating committee: the seventh report of the joint national committee on prevention, detection, evaluation, and treatment of high blood pressure: the JNC 7 report. Jama, 2003;289:2560-2572.

12. Arrondel, Christelle, et al. Expression of the nonmuscle myosin heavy chain IIA in the human kidney and screening for MYH9 mutations in Epstein and Fechtner syndromes. J Am Soc Nephrol, 2002;13.1:65-74.

13. Marini MBM, Pecci A, Romagnoli R, Musante L, Candiano G, Ghiggeri GM, Balduini C, Seri M, Marini M, Bruschi M, Pecci A, Romagnoli R, Musante L, Candiano G, Ghiggeri GM, Balduini C, Seri M,Marini M, Bruschi M, Pecci A, Romagnoli R, Musante LC, Non-muscle myosin heavy chain iia and iib interact and co-localize in living cells: Relevance for myh9-related disease. 2016;41(6).

14. Cheng, Wenrong, et al. Polymorphisms in the nonmuscle myosin heavy chain 9 gene (MYH9) are associated with the progression of $\lg A$ nephropathy in Chinese. Nephrol Dial Transplant, 2011;26.8:2544-2549.

15. Behar, DM., et al. African ancestry allelic variation at the MYH9 gene contributes to increased susceptibility to non-diabetic end-stage kidney disease in Hispanic Americans. Human Mol Genet, 2010;19.9:1816-1827.

16. Pattaro, Cristian, et al. Genome-wide linkage analysis of serum creatinine in three isolated European populations. Kidney Int, 2009:76.3:297-306.

17. Kopp, Jeffrey B., et al. MYH9 is a major-effect risk gene for focal segmental glomerulosclerosis. Nat Genet, 2008:40.10:1175-1184.

18. Liu, Liping, et al. Association of MYH9 polymorphisms with hypertension in patients with chronic kidney disease in China. Kidney Blood Press Res, 2016;41.6:956-965

19. Freedman, Bl., et al. The non-muscle Myosin heavy chain 9 gene (MYH9) is not associated with lupus nephritis in African Americans. Am J Nephrol, 2010;32.1:66-72.

20. Lipkowitz, MS, et al. Association analysis of the non-muscle myosin heavy chain 9 gene (MYH9) in hypertensive nephropathy: African American Study of Kidney Disease and Hypertension (AASK). J Am Soc Nephrol, 2009;20:56A.

21. Palaniappan, L, Carnethon, M, Fortmann, SP. Association between microalbuminuria and the metabolic syndrome: NHANES III. Am J Hypertension, 2003;16.11:952-958.

22. Kaur, J. Assessment and screening of the risk factors in metabolic syndrome. Med Sci, 2014;2.3:140-152.

23. Katzmarzyk, PT., et al. Targeting the metabolic syndrome with exercise: evidence from the HERITAGE Family Study. Med Sci Sports Exercise, 2003:35.10:1703-1709.

24. Bahreinian, Maryam, and Ahmad Esmaillzadeh. "Opinion: quantity and quality of carbohydrate intake in Iran: a target for nutritional intervention." (2012): 648-649.

25. Tabatabaei-Malazy O, Qorbani M, Samavat T, Sharifi F, Larijani B, Fakhrzadeh $H$. Prevalence of dyslipidemia in Iran: a systematic review and meta-analysis study. Int J Prev Med. 2014;5(4):373.

26. Nelson ME, Rejeski WJ, Blair SN, Duncan PW, Judge JO, King AC, et al. Physical activity and public health in older adults: recommendation from the American College of Sports Medicine and the American Heart Association. Med Sci Sports Exercise. 2007;39(8):1435-45.
27. Koochek A, Johansson S, Kocturk T, Sundquist J, Sundquist K. Physical activity and body mass index in elderly Iranians in Sweden: a populationbased study. Eur J Clin Nutr. 2008;62(11):1326-32.

28. Simoes EJ, Kobau R, Kapp J, Waterman B, Mokdad A, Anderson L. Associations of physical activity and body mass index with activities of daily living in older adults. J Commun Health. 2006;31(6):453-67.

29. Bayram F, Kocer D, Gundogan K, Kaya A, Demir O, Coskun R, et al. Prevalence of dyslipidemia and associated risk factors in Turkish adults. J Clin Lipidol. 2014:8(2):206-16.

30. Karpov Y, Khomitskaya Y. PROMETHEUS: an observational, cross-sectional, retrospective study of hypertriglyceridemia in Russia. Cardiovasc Diabetol. 2015;14(1):115

31. Abujbara M, Batieha A, Khader Y, Jaddou H, El-Khateeb M, Ajlouni K. The prevalence of dyslipidemia among Jordanians. J Lipids. 2018;2018.

32. Penesova A, Cizmarova E, Belan V, Blazicek P, Imrich R, Vlcek M, et al. Insulin resistance in young, lean male subjects with essential hypertension. J Human Hypertension. 2011;25(6):391-400.

33. Sinha S, Qazi SA, Banik S, Islam MZ. Correlation study of insulin resistance and essential hypertension among Bangladeshi male volunteers. J Young Pharm. 2015:7(3):200.

34. Sarafidis P, Lasaridis A, Nilsson P, Pikilidou M, Stafilas P, Kanaki A, et al. Validity and reproducibility of HOMA-IR, 1/HOMA-IR, QUICKI and McAuley's indices in patients with hypertension and type II diabetes. J Human Hypertension. 2007;21(9):709-16.

35. Schillaci G, Reboldi G, Verdecchia P. High-normal serum creatinine concentration is a predictor of cardiovascular risk in essential hypertension. Arch Intern Med. 2001;161(6):886-91.

36. Kumar A, Rekha N, Raghav ED. A Study of microalbuminuria in patients with essential hypertension. Int J Contemp Med Res. 2016.

37. Liu L, Wang C, Mi Y, Liu D, Li L, Fan J, et al. Association of myh9 polymorphisms with hypertension in patients with chronic kidney disease in china. Kidney Blood Pressure Res. 2016;41(6):956-65.

38. Masconi K. The occurance of genetic variations in the MYH9 gene and their association with CKD in a mixed South African population: Stellenbosch: Stellenbosch University; 2012.

39. Bondzie PA. New insights into the molecular regulation of kidney disease: contributions of APOL1 and MYH9: Boston University; 2014.

40. Zhao H, Ma L, Yan M, Wang Y, Zhao T, Zhang H, et al. Association between MYH9 and APOL1 gene polymorphisms and the risk of diabetic kidney disease in patients with Type 2 diabetes in a Chinese Han population. J Diab Res. 2018;2018.

41. Ling C, Cai C, Chang B, Shi W, Wei F, Yu P, et al. MYH9 gene polymorphisms may be associated with cerebrovascular blood flow in patients with type 2 diabetes. Genet Mol Res. 2015;14(1):1008-16.

42. Franceschini N, Voruganti VS, Haack K, Almasy L, Laston S, Göring HH, et al. The association of the MYH9 gene and kidney outcomes in American Indians: the Strong Heart Family Study. Human Genet. 2010;127(3):295-301.

This work is licensed under a Creative Commons Attribution-NonCommercial 3.0 Unported License which allows users to read, copy, distribute and make derivative

works for non-commercial purposes from the material, as long as the author of the original work is cited properly. 